\title{
Biological and Quantitative Issues in Neuropsychiatry
}

\author{
G. E. BERRIOS ${ }^{1}$ and T. R. DENING ${ }^{2}$ \\ 'Department of Psychiatry, University of Cambridge, Addenbrooke's Hospital (Level 4), Hills Road, \\ Cambridge, CB2 2QQ UK \\ ${ }^{2}$ Zohn Radcliffe Hospital, Oxford, UK
}

Correspondence: G. E. Berrios at above address

\begin{abstract}
During the recent resurgence of interest in neuropsychiatry, rapid technological advances have outpaced developments in the underlying theoretical framework. Neurophilosophy has tended to overlook clinical problems. This paper aims to redress the balance by examining a number of conceptual issues. Two groups of problems are considered: those related to brain functioning and psychiatric symptoms, and those related to the measurement of symptoms and their statistical analysis. It is emphasized that psychiatric symptoms appear to reflect the modular organization of the brain; and the particular psychiatric symptomatology associated with individual neurological diseases may be more distinct than is generally assumed, both cross-sectionally and over time.
\end{abstract}

\section{Introduction}

Neuropsychiatry has undergone a revival in recent years. It was last predominant between about 1860 and the Great War, before going into decline. During the 19th century, the so-called anatomo-clinical model of disease (ACM) (Ackerknecht, 1967) provided the theoretical basis for an organic view of psychiatry. In our view, and despite current sophisticated research instrumentation, the underlying conceptual matrix has not advanced beyond this 19th century model. There has been, however, a change in style: the first "organicist" period was accompanied by persistent and relevant "philosophizing", but the current period has adopted a positivist stance, namely that instrumental sophistication and hard empirical work obviate the need for concepts. The few books that have attempted a conceptual analysis of these problems neglect the clinical aspects (Churchland, 1986; Wulf et al., 1986; Spitzer et al., 1988; Hundert, 1989).

Neuropsychiatry is a term currently applied to the study of psychiatric manifestations of cerebral diseases. Its practitioners recognize the conceptual limitations of the ACM, but few efforts have been made to improve upon this model. Some authorities appear to espouse a version of the ACM. Others may not agree with the model but are indifferent to analysis of concepts (because it is believed either that 20th century research should be "atheoretical" and unencumbered by "philosophical" issues or that current sophistication in measurement and techniques will overcome underlying confusions).

$0953-4180 / 90 / 040247+13 \$ 3.50 / 0 \quad$ (C) 1990 GNS (Clinical Neuroscience) Publishers 
This paper adopts the view that concepts, and the manner in which they have developed, are important. Below we consider the current status of views regarding the pathogenesis of mental symptoms in organic psychiatry. These views are found locked into various dichotomous approaches. These dichotomies will be considered, together with the relatively neglected question of the limitations of conventional quantitative approaches to these problems.

\section{Pathogenesis of Mental Symptoms}

\section{Organic versus reactive and organic versus functional}

Controversy surrounds the origin of mental disorders accompanying neurological disease. Do they arise directly from brain lesions or are they psychological "reactions" (Starobinski, 1977; Degwitz, 1986)? Authors have adopted views at either extreme (Brain, 1930; Hunter, 1973) but most have intermediate opinions. The limitations of conventional correlational methodology make it impossible to clarify this issue by carrying out a crucial empirical test. A common view is that a positive correlation between say, motor impairment and depression in Parkinson's disease suggests that the affective disorder is reactive in nature (Mindham, 1974; Gotham et al., 1986). The opposite conclusion, that a lack of correlation between disease severity and depression supports a reactive hypothesis, has also been drawn (Bieliauskas and Glantz, 1989). In fact, neither argument follows, for both the organic and the reactive models are consistent with either observation.

Another view may be that if life events are found to correlate with affective but not motor symptoms, this is a further indication of "reactivity". This is fallacious as life events are superimposed occurrences which also happen in subjects who are not neurologically ill, and thus no light is cast on intrinsic mechanisms.

A possible solution to the "reactivity issue" is to identify patterns within the data that show simultaneous associations and dissociations involving certain neurological symptoms and certain psychiatric variables. Such patterns may prove inconsistent with the "reactive hypothesis" (Dening and Berrios, 1989). This multidimensional strategy is based on the view that (a) psychiatry and neurology arise from the same substratum, (b) neurological and psychiatric symptoms have different thresholds for expression, and (c) these thresholds and the triggering of the symptoms are controlled by intermediate variables (Berrios and Quemada, 1990). The latter may include age, sex, genetic loading, concomitant diseases, life stresses and treatment.

A further dichotomy is that existing between "organic" and "functional". disorders, an extension of Cartesian dualism which forms the basis of modern psychiatry (Hundert, 1989). Dualism was also instrumental in the development of physiology as it spared scientists from the heresy of investigating the mind as a God-given entity, thus freeing the body for mechanical analysis (Hall, 1969). The term "functional" has, however, had 
several meanings (Ruckmich, 1913; Dallenbach, 1915; Trimble, 1982) and probably all these have outlived their usefulness. Clinically, it is defined by exclusion, i.e. as a situation in which no "organicity" is found. This definition is weak, since at best it is parasitical upon the sensitivity of current tests. At worst, it may simply reflect the observation that a particular symptom does not correspond to a putative anatomical territory.

Positive definitions of "functional" are lacking. Those based on psychodynamic theory, on putative secondary gains, on personality, on theories of dissociation and conversion, on malingering, etc., are notoriously unreliable and their origin betrays the 19th century dualism, according to which "organicity" was defined in anatomical terms. As the definition of "organic" moves from the molar to the molecular, the term "functional" loses its meaning.

Further problems exist with the use of the word "functional" in that the disorders commonly known as "functional psychoses" are increasingly shown to be associated with altered brain activity and structural changes. This has long been known in schizophrenia and recently suggested in the affective disorders, especially in the elderly (Alexopoulos, 1989; Morris and Rapoport, 1990). Much energy has been expended on the correct classification of psychiatric disorders arising as "secondary" to organic brain disease (APA, 1987; Tucker et al., 1990). In this regard the question is whether this distinction is being rendered redundant by technical advances. Two views can be expressed on this depending on how strictly the modular view is upheld. The economical view would dictate that a symptom-cluster (characterizing a disease) is generated by pathological changes in a given modular cluster. Thus the "schizophrenia" of temporal lobe epilepsy and "real" schizophrenia would be the same as both would express the same modular disturbance, despite their different aetiologies. The second view, which we should like to suggest, preserves the primary/secondary distinction (which we consider as useful) and allows for the fact that both are organic. Here "real" schizophrenia and TLE schizophrenia would arise from disturbance in different modular clusters (modular issues are discussed in section 3).

\section{Specific versus non-specific disorders}

In the 19th century view, each physical disease was associated with its own characteristic form of insanity (Bleuler, 1966). This view was challenged, most notably by Bonhoeffer (1910) who proposed the concept of nonspecific exogenous psychoses or reaction-types and by Hoche (1912) who reintroduced the concept of symptom-complex. Bonhoeffer postulated the existence of two or three stereotyped "wired-in" forms of behaviour which could be triggered by any cerebral lesion, regardless of nature or localization. Hoche, in turn, went back to Griesinger's notion of syndromes. These could have either organic or psychological origin and occur in any form of insanity. Both Bonhoeffer's and Hoche's views were not the result of empirical research but originated in the contemporary reaction against 
localizationism. Their gestaltic view of stereotyped syndromes was useful in controlling the excesses of the "illness-specific insanity" view but discouraged research. If all physical illnesses produce similar mental reactions, little can be learned from comparative studies.

A recent example of this problem is the tendency to accept that the affective disorder of neurological disease is of the same nature as that of major depression (nature here meaning internal structure and aetiology of symptoms) (Rodin and Voshart, 1986). Neurological patients with particular mixtures of physical and mental symptoms are often labelled as having major depression. This led to overdiagnosis of depression in neurology. Only recently have efforts been made to separate these "behavioural phenocopies" (symptom complexes that may by chance resemble recognized psychiatric disorders) from "real" major depression, and to create instruments capable of their differentiation (Berrios and Samuel, 1987). For example, it appears as if guilt is less common in phenocopies. In this regard, due to the potentially different underlying mechanisms, it is possible that different neurological diseases may be accompanied by varying patterns of affective symptoms.

The non-specific view has tended to hold sway throughout the 20th century (Davison and Bagley, 1969; Lishman, 1987). Its strength resides in the emphasis on the common ground between different neuropsychiatric disorders, concentrating on general patterns such as delirium, dementia, mental retardation, schizophrenia-like psychoses, and depression. However, a more specific approach is offered by the development of sophisticated instruments and statistical methods. Investigators in the field of mental handicap, for example, are regaining interest in the contrasting deficits in different diagnostic groups (Burack et al., 1988). We suggest a neo-Kahlbaumian compromise which combines a syndrome-based approach with recognition of the characteristic symptom patterns of certain individual diseases.

\section{Modular versus non-modular disorders}

The questions discussed above can also be examined from the perspective of theories concerning the relation of mental symptoms to the brain itself. Several theories regarding the modularity of brain functioning have been proposed, ranging from stringent models which require almost complete independence of individual modules (Fodor, 1983; Marshall, 1984) to models where systems vary in their degree of modularity (Shallice, 1988). However, all such theories contain two basic assumptions: (a) that certain psychological functions are based upon autonomous programmes, which can perform routines with minimal involvement of other programmes or modules; and (b) that the brain is physically parcelled out so that programmes are sited and their functioning hardware-dependent (Fodor, 1983). Historically, these two assumptions inspired phrenology and much of the important brain localization work during the 19th century (Berrios, 1988). 
The fortunes of the modular and antimodular views have fluctuated throughout the history of mind-brain relationships, but modularity is currently in the ascendant. Evidence for modularity is derived from computer science, linguistics, neurophysiology and cognitive psychology (Johnson-Laird, 1983; Shallice, 1988). Certain functions are undoubtedly modular (e.g. motor, sensory, language) but others seem less so (e.g. memory, judgment, intelligence).

These principles should be applied to mental symptoms as much as to normal function. The 19th century ACM naturally inclined towards modularity, but it had difficulty explaining many mental symptoms because of the bias towards topographical rather than circuit localization. In addition, it had no machinery to predict which symptoms are or are not localized, and if so in what fashion. To improve upon the ACM it is suggested here that functions may be considered to exist at three levels of modularity: (a) "phrenological", according to which functions are sited in that part of the brain whose dysfunction may give rise to the symptom (e.g. voluntary motor activity); (b) "vestigial", where the affected brain area may contain modules not normally active (i.e. having no normal expression) but whose dysfunction produces the symptom (e.g. frontal lobe); and (c) a "general resource" interpretation, which postulates the existence of a diffuse module (e.g. attention) whose function is to support other modules and whose impairment affects other localized functions (e.g. memory).

It is important to consider the modularity status of psychiatric symptoms. We suggest that they constitute a heterogeneous group of behaviours whose degree of association with a particular module varies according to their level of semantic organization (which may range from neuronal to social). Symptoms can be conceived of as signals enveloped in varying amounts of noise. When dysfunction in a recognizable module produces a given symptom, the signal is clear, and the noise (psychosocial factors) less perturbing. When the symptom is the manifestation of dysfunction in a general resource, the signal is less recognizable because the resource rarely shows separately.

For example, a hallucination may be a direct manifestation of a modular dysfunction. However, its content, timing, and level of insight (the noise) may depend upon factors external to that module. As perception is a discrete function, it should be possible to disentangle these confounding elements. In contrast, dysfunction in a general resource such as "effort" or "sticking power" will not show by itself but will affect a wide range of modular activity (e.g. memory, perception, language). In this case the psychiatrist would be unaware of the failure in this resource, unless there was a specific test. In general, tests to evaluate specific modules are easier to construct for their activity is more readily defined and represented (Andrich, 1988). General resources, not having specific expression, may require measurement of proxy variables and the use of techniques such as latent trait analysis (McCutcheon, 1987).

Researchers and clinicians inevitably make assessments as to the likely degree of modularity, both of the neurological disorder and of the psychi- 
atric symptoms. Such decisions will affect the conclusions reached as to the origin and course of the psychiatric symptoms.

\section{Quantitative Approaches}

\section{Categories versus dimensions and probabilities}

Organic psychiatry is affected by issues relating to the measurement and conceptualization of the data gathered, including taxonomy, the nature and significance of symptoms, the roles of introspection and external observation, and the identification of cases. These apparently disparate aspects of clinical research are all related to a deeper dichotomy: that between rival systems of measurement, as exemplified by the work of Fisher on the one hand and Neyman and Pearson on the other (Howson and Urbach, 1989).

Perhaps the most important change affecting the concepts of description and evidence in early 20th century psychology has been the gradual replacement of the deterministic, Newtonian view by a probabilistic approach, according to which the perception and processing of information depend upon decisions taken by the mind. Such decisions depend on the strength of the signal, the surrounding noise, and the state of the system itself (cognitive, affective, etc.). Perception was the first psychological function investigated by the new approach, signal detection models being an example. Cognition followed, particularly in relation to problem solving (Meyering, 1989). The mind was described as a statistician, and what started as a metaphor soon became a powerful model of explanation (Gigerenzer et al., 1989). In this debate Fisher attempted to preseve a form of determinism in his choice of statistical and significance cut-off points. Neyman and the younger Pearson based their view on a probabilistic account of the mind (Howson and Urbach, 1989).

Little is known about how this debate has affected psychiatry. It is likely that at the time of the dispute it did not impinge, as psychiatry still used a categorical framework. However, the issues have become relevant to descriptive psychopathology as they provide a model for understanding the way in which subjects decide which experiences to report, and also how clinicians decide which symptoms, and at what intensity, are significant for diagnosis.

This is of particular relevance to classification where several approaches exist. DSM-III-R (APA 1987), the currently-ascendant categorical system, has a range of organic symptomatic disorders, e.g. Organic Affective Disorder, Organic Delusional Disorder. This recognizes that psychiatric disorder may arise directly from brain disease, presumably from substrates different from those of schizophrenia or primary affective disorders. However, a judgment about aetiology has to be made but DSM-III-R has difficulty in dealing with the possibility, for instance, of coincidental major depression. An alternative categorical approach is to make a psychiatric diagnosis, using a standard classification, as if no physical illness were present. This is more neutral as to aetiology, and useful for communicating 
severity or symptom profile to other psychiatrists. However, no account is taken of possible interactions between the symptoms and the underlying neurological illness; and furthermore, equivalence to conventional psychiatric diseases (depression, schizophrenia, etc.) is implied. Thirdly, an empirical typology may be developed, especially if symptom clusters do not fit into any standard classification (Dening and Berrios, 1989). This can accommodate hypotheses about underlying mechanisms, but may not be applicable to other neurological disorders. Fourthly, some of the pitfalls of categorical taxonomy may be avoided by using dimensional measures, i.e. "symptoms not syndromes" (Persons, 1986). Although a formal taxonomy is then not necessary, some form of grouping is inevitable to ascertain similarities and differences between cases. We suggest that currently there exists no ideal taxonomy for neuropsychiatry, and researchers should consider using more than one approach.

Psychiatric "caseness" among neurological and medical patients (Goldberg, 1985; House, 1988) can also be understood in terms of the categoricaldimensional debate. It remains unclear whether cases differ qualitatively or quantitatively from non-cases (the latter suggested by the continuous distribution of scores). Recent research has tended to define cases epidemiologically from distributions on linear scales (House, 1988), whereas clinically cases are still identified in a categorical manner, by means of syndromes. These two methods of case definition are often confused. The utility of identifying cases by means of threshold scores on screening instruments has been advocated (Goldberg, 1985) and criticised (Kirk and Saunders, 1979; Metcalfe et al., 1988). Most instruments used have been developed in nonneurological populations, with validity not yet established in neurological settings. Furthermore, underlying patterns of scoring may differ from those in non-neurological cases.

\section{Old versus new approaches to symptoms}

"Symptoms without names" constitute another problem for organic psychiatry. These are experiences and behaviours, relevantly associated with neurological disease, for which no psychopathological terms exist. Such phenomena are often disregarded or forced into the domain of other symptoms. For example, subjects with Parkinson's disease may experience curious changes in perception of the passage of time which are either not rated by the usual instruments or are rated as confusion or memory disorder. Creative work in psychopathology has been restricted by the "closure" phenomenon in current clinical glossaries, where psychiatric nosology is constructed from a circumscribed number of chosen symptoms.

Some other symptoms are neglected (e.g. anxiety, irritability) since they are considered to have less discriminant value. This is true in relation to conventional psychiatric syndromes, but not necessarily so in organic disorders. Their neglect in this area is perhaps unjustified.

The relative merits of subjective (symptoms) and objective (signs) clinical features remain important. Traditionally, signs are thought to 
convey more information than symptoms but even inferences from signs may be misleading, e.g. motor retardation in Parkinson's disease may exaggerate the apparent degree of depression or cognitive impairment (and vice versa). The emphasis on symptoms reflects the value placed upon introspection as a clinical technique and the estimated truthfulness of subjects. During then 19th century these were rated high (Boring, 1953; Danziger, 1980). Behaviourism and psychoanalysis cast doubt on the worth of conscious utterances and devalued introspective information. However, another period of credulity is current and most self- and observer-rated instruments utilize subjects' declarations (Pilkington and Glasgow, 1967).

A possible alternative method of collecting signals may use so-called "microsymptoms", i.e. signals which do not reach the subject's consciousness and which are often beyond the perceptual range of the observer (hence, not "signs" in the traditional sense). Such microsymptoms, high in signal value and low in psychosocial noise, are collected by means of instrumentation and should become important in the development of neuropsychiatry. Microsymptoms which may prove of use include reaction times, blink rates, and soft neurological signs.

\section{Chance versus non-chance associations}

As mentioned above, the most important conceptual legacy of the ACM was the idea that brain sites, when distressed by a pathological change, give rise to identifiable behavioural signals (which may be psychiatric symptoms). Unfortunately, without a clear pathogenetic hypothesis, the correlational model may give rise to spurious associations, i.e. chance symptoms might be incorrectly related to brain sites. Historically, a major difference between neurology and psychiatry was that the former anchored signals to sites by means of physiological theory (particularly motor and sensory function) more successfully than psychiatry.

The renaissance of organic psychiatry has emphasized this difficulty. Simplistic correlations abound: strokes affecting the left frontal pole are said to be related to "depression" (Robinson and Chait, 1985); lesions of the right temporal lobe to delusions (Price and Mesulam, 1985); or musical hallucinations (Berrios, 1990); and those of the non-dominant hemisphere to affective disorder (Ross and Rush, 1981). These input-output (black-box type) correlations are based on statistical significance, and do exhibit modest predictive value. To avoid spurious correlations knowledge of the mechanisms involved is essential.

Another problem relates to the "contemporaneity" of lesion and signal. Correlations are informational only when the symptom is correlated with a simultaneous brain change which has been detected "hic et nunc". This rarely happens in clinical practice. Usually, lists of symptoms are correlated either with lesions discovered during life but of unknown duration, or with postmortem findings (Damasio and Damasio, 1989). Both may lead to false correlations. If detected during life, the lesion may have fortuitously preceded the symptom; and in post-mortem cases, the temporal sequencing 
of the symptoms cannot be deduced from or associated meaningfully with the brain lesions.

A third source of chance findings and correlation relates to neuropsychological testing techniques. If significant dissociations are obtained between two tests each purporting to measure separate functions, then the conclusion is drawn that the functions are differentially compromised. That is, if scores are abnormal in one test, but normal in the other, the investigator might conclude that the illness has affected one brain site but not another. However, the point is often missed that the differential result may be due to the sensitivity of the tests and not to the level of functioning of the sites themselves. Ideally, the tests should be equally sensitive, but, in practice, no external yardstick is available.

\section{Linear correlations versus multivariate and longitudinal measurements}

Traditional studies of psychiatric features of neurological disease have taken a cross-sectional view, examining the cases for both components at (more or less) the same point in time, and searching for linear correlations between the two. We suggest that this methodology has reached the limit of its utility.

In addition to the obvious point that linear correlations cannot identify causes, correlations may also be spuriously inflated, either because the instruments used to measure physical and psychological function are influenced by a common factor (a frequent example being poor cognitive test performance by subjects who cannot respond due to motor disability), or because a third (unknown) variable is in operation. Subjects are likely to be seen when in hospital or attending clinics, so the sampling procedure may operate in favour of positive correlations. Such cross-sectional correlations may also overlook the causation of psychiatric disorder by neurologically silent lesions, e.g. in multiple sclerosis (Berrios and Quemada, 1990).

On the other hand, if the relationship between psychiatry and neurology is either non-linear or not simultaneous, the correlational method may lead to type 2 errors. For example, physical events may precede (by months or years) psychiatric changes in disorders such as multiple sclerosis and Parkinson's disease. If so, a cross-sectional approach will miss much relevant information and fail to demonstrate the true course of events.

A further problem is the potential confusion between correlations derived from analysis of groups and individuals. Group data are most commonly used in organic psychiatry. The variable "time" is not an intrinsic component of cross-sectional cohort studies (Kelly and McGrath, 1988). However, since patients in a cohort are studied at different stages of their disease, it is assumed that the lack of simultaneity is corrected for. This is unlikely to be the case because the patients are not recruited at random moments and because the arrow of time moves in the same direction, that is, early events in the causal chain are consistently missed. To determine the real nature of a correlation, it may be of more value longitudinally to study serial pairs of values for single individuals, as in this case the time variable is an intrinsic part of the process (Strauss et al., 1985). 
Powerful statistical techniques, such as factor and latent trait analyses and cluster analysis utilize the internal structure of cross-sectional data to identify patterns of variables and of cases, respectively. Other techniques (analyses of variance, log-linear models) enable the analysis of longitudinal data. The use of "summary measures" has been recently advocated (Matthews et al., 1990).

It is also necessary to develop hypotheses which take into account the natural history of each neurological disorder. For example, different models are required to describe progressive (e.g. Alzheimer's disease), fluctuating (e.g. multiple sclerosis), and potentially reversible or preventable disorders (e.g. Wilson's disease). This gives some statistical support to the point made above concerning the inflexibility of the Bonhoefferian, non-specific view. However, in seeking non-simultaneous associations, it is not easy to know which intervals or points in time are important. This problem can be understood in terms of an analogue-to-digital conversion task, that is, the determination of the appropriate sampling rate is crucial to the validity of the transformation. If observations are insufficiently frequent the relevant morbid events and their effects will be missed.

\section{Conclusions}

We conclude that attempting to understand the effects of brain disease upon behaviour and subjective experience is a major challenge for medicine. Any investigation in this field will be influenced by a number of overlapping issues, which this paper has tried to clarify. In particular, it is argued that:

1 Conventional methodologies are ill-equipped to distinguish between mental symptoms arising from physical and psychological mechanisms, but the use of pattern recognition techniques may be useful.

2 The Bonhoefferian and Hochean concepts of non-specific reactiontypes have been overstated, and should be modified in the light of recognition of characteristic patterns of mental symptoms in different neurological disorders. More research is required into separating behavioural phenocopies from real diseases.

3 Many psychiatric symptoms reflect, to varying degrees, modular brain functioning. Those with specific modules produce clear signals and should be of particular value in understanding mental activity. Those related to general resource modules are more difficult to study in isolation. Other symptoms may consist entirely of psychosocial elements and convey no information about the brain at all.

4 Spurious associations may easily arise from misunderstandings of the limitations of neuropsychological testing and of correlational statistics. Researchers should beware against these pitfalls.

5 Neuropsychiatric studies have so far tended to take a cross-sectional view. We suggest that it is necessary to employ statistical advances which enable multivariate analyses and the examination of longitudinal data. It is particularly important to incorporate the dimension of time into neuro- 
psychiatric research, and to develop specific models for individual neurological diseases.

6 Both categorical and dimensional approaches to data are valuable but awareness of their strengths and weaknesses is required.

7 Symptoms which are neglected in general psychiatry as being nonspecific may have more discriminant power in organic psychiatry. Diagnostic discrimination may also be improved by the investigation of "microsymptoms" and of "symptoms without names".

\section{References}

Ackerknecht, E. (1967). "Medicine at the Paris Hospital 1794-1848”. Johns Hopkins Press, Baltimore.

Alexopoulos, G. S. (1989). Late-life depression and neurological brain disease. International Fournal of Geriatric Psychiatry, 4, 187--190.

American Psychiatric Association. (1987). "Diagnostic and Statistical Manual of Mental Disorders (Third Edition-Revised): DSM-III-R". American Psychiatric Association, Washington, DG.

Andrich, D. (1988). "Rasch Models for Measurement". Sage Publications, Newbury Park, California.

Berrios, G. E. (1988). Historical background to abnormal psychology. In "Adult Abnormal Psychology" (Eds E. Miller and P. J. Cooper). Churchill Livingstone, Edinburgh, 26 51.

Berrios, G. E. (1990). Musical hallucinations: a historical and clinical study. British fournal of Psychiatry, 156, 188-194.

Berrios, G. E. and Samuel, C. (1987). Affective disorder in the neurological patient. Fournal of Nervous and Mental Disease, 175, 173-176.

Berrios, G. E. and Quemada, J. I. (1990). Depressive illness in multiple sclerosis. Clinical and theoretical aspects of the association. British Fournal of Psychiatry, 156, 10-16.

Bieliauskas, L. A., Glantz, R. H. (1989). Depression type in Parkinson's disease. Journal of Clinical and Experimental Neuropsychology, 11, 597-604.

Bleuler, M., Willi, J. and Bühler, H. R. (1966). "Akute Psychische Begleiterscheinungen körperlicher Krankheiten ('Akuter exogener Reaktions-Typus'). Übersicht und neuer Forschungen". 'Thieme Verlag, Stuttgart.

Bonhoeffer, K. (1910). "Die Symptomatischen Psychosen". Deuticke, Leipzig.

Boring, E. G. (1953). A history of introspection. Psychological Bulletin, 50, 169-189.

Brain, W. E. (1930). Critical review: disseminated sclerosis. Quarterly Fournal of Medicine, 23, 343-391.

Burack, J. A., Hodapp, R. M. and Zigler, E. (1988). Issues in the classification of mental retardation: differentiating among organic aetiologies. Fournal of Child Psychology and Psychiatry, 29, 765-779.

Churchland, P. (1986). "Neurophilosophy". MIT Press, Cambridge, Mass.

Dallenbach, K. M. (1915). The history and derivation of the word "function" as a systematic term in psychology. American Fournal of Psychology, 26, 473-484.

Damasio, H. and Damasio, A. R. (1989). "Lesion Analysis in Neuropsychology". Oxford University Press, New York.

Danziger, K. (1980). The history of introspection reconsidered. Fournal of the History of the Behavioural Sciences, 16, 241-262.

Davison, K., Bagley, C. R. (1969). Schizophrenia-like psychoses associated with organic disorders of the central nervous system: a review of the literature. In "Current Problems in Neuropsychiatry: Schizophrenia, Epilepsy, the Temporal Lobe" (Ed. R. N. Herrington). British Journal of Psychiatry Special Publication No. 4. Headley Brothers, Ashford, Kent, pp. 113-184.

Degwitz, R. (1986). Der Begriff Reaktion in der Psychiatrie und seine Bedeutung für das Menschenbild des Psychiaters. Nervenarzt, 57, 96-99. 
Dening, T. R. and Berrios, G. R. (1989). Wilson's disease: psychiatric symptoms in 195 cases. Archives of General Psychiatry, 46, 1126-1134.

Fodor, J. A. (1983). "The Modularity of Mind". MIT Press, Cambridge, Mass.

Gigerenzer, G., Swijtink, Z., Porter, T., Daston, L., Beatty, J. and Krüger, L. (1989). "The Empire of Chance: How Probability Changed Science and Everyday Life". Cambridge University Press, Cambridge.

Goldberg, D. (1985). Identifying psychiatric illness among general medical patients. British Medical Journal, 291, 161-162.

Gotham, A.-M., Brown, R. G. and Marsden, C. D. (1986). Depression in Parkinson's disease: a quantitative and qualitative analysis. Journal of Neurology, Neurosurgery and Psychiatry, 49, 381-389.

Hall, T. S. (1969). "Ideas of Life and Matter: Studies in the History of General Physiology $600 \mathrm{BC}$ to $1900 \mathrm{AD}$. Volume 1: From Pre-Socratic Times to the Enlightenment". University of Chicago Press, Chicago, pp. 250-263.

Hoche, A. (1912). Die Bedeutung der Symptomenkomplex in der Psychiatrie. Zeitschrift für die gesamte Neurologie und Psychiatrie, 12, 540-551.

House, A. (1988). Mood disorders in the physically ill-problems of definition and measurement. Fournal of Psychosomatic Research, 32, 345-353.

Howson, C. and Urbach, P. (1989). "Scientific Reasoning: the Bayesian Approach". Open Court, La Salle, Illinois.

Hundert, E. M. (1989). "Philosophy, Psychiatry and Neuroscience: Three Approaches to the Mind: a Synthetic Analysis of the Varieties of Human Experience". Oxford University Press, Oxford.

Hunter, R. (1973). Psychiatry and neurology: psychosyndrome or brain disease. Proceedings of the Royal Society of Medicine, 66, 359-364.

Johnson-Laird, P. N. (1983). "Mental Models". Cambridge University Press, Cambridge.

Kelly, J. R. and McGrath, J. E. (1988). "On Time and Method". Sage Publications, Newbury Park, California.

Kirk, C. A. and Saunders, M. (1979). Psychiatric illness in a neurological out-patient department in North East England: use of the General Health Questionnaire in the prospective study of neurological out-patients. Acta Psychiatrica Scandinavica, 60, 427-437.

Lishman, W. A. (1987). "Organic Psychiatry: the Psychological Consequences of Cerebral Disorder", 2nd edn. Blackwell, Oxford.

McCutcheon, A. L. (1987). "Latent Class Analysis". Sage Publications, Newbury Park, California.

Marshall, J. C. (1984). Multiple perspectives on modularity. Cognition, 17, 209-242.

Matthews, J, N. S., Altman, D. G., Campbell, M. J. and Royston, P. (1990). Analysis of serial measurements in medical research. British Medical fournal, 300, 230-235.

Metcalfe, R., Firth, D., Pollock, S. and Creed, F. (1988). Psychiatric morbidity and illness behaviour in female neurological in-patients. Journal of Neurology, Neurosurgery and Psychiatry, 51, 1387-1390.

Meyering, T. C. (1989). "Historical Roots of Cognitive Science". Kluwer Academic Publishers, Dordrecht.

Mindham, R. H. S. (1974). Psychiatric aspects of Parkinson's disease. British Journal of Hospital Medicine, 11, 411-414.

Morris, P. and Rapoport, S. I. (1990). Neuroimaging and affective disorder in late life: a review. Canadian Fournal of Psychiatry, 35, 347-354.

Persons, J. B. (1986). The advantages of studying psychological phenomena, rather than psychiatric diagnoses. American Psychologist, 41, 1252-1260.

Pilkington, G. W. and Glasgow, W. D. (1967). Towards a rehabilitation of introspection as a method in psychology. Journal of Existentialism, 7, 329-350.

Price, B. H. and Mesulam, M. (1985). Psychiatric manifestations of right hemisphere infarctions. Journal of Nervous and Mental Disease, 173, 610-614.

Robinson, R. G. and Chait, R. M. (1985). Emotional correlates of structural brain injury with particular emphasis on post-stroke disorders. CRC Critical Reviews in Clinical Neurology, 1, 285-318. 
Rodin, G. and Voshart, K. (1986). Depression in the medically ill: an overview. American Journal of Psychiatry, 143, 696-705.

Ross, E. D. and Rush, A. J. (1981). Diagnosis and neuroanatomical correlates of depression in brain-damaged patients: implications for a neurology of depression. Archives of General Psychiatry, 38, 1344-1354.

Ruckmich, C. A. (1913). The use of the term "function" in English textbooks of psychology. American Fournal of Psychology, 24, 99-123.

Shallice, T. (1988). "From Neuropyschology to Mental Structure". Cambridge University Press, Cambridge.

Spitzer, M., Uehlein, F. A. and Oepen, G. (Eds). (1988). "Psychopathology and Philosophy". Springer-Verlag, Berlin.

Starobinski, J. (1977). The word reaction: from physics to psychiatry. Psychological Medicine, 7, 373-386.

Strauss, J. S., Hafez, H., Lieberman, P. and Harding, C. M. (1985). The course of psychiatric disorder, III: longitudinal principles. American Fournal of Psychiatry, 142, 289-296.

Trimble, M. R. (1982). Functional diseases. British Medical fournal, 285, 1768-1770.

Tucker, G., Popkin, M., Caine, E., Folstein, M. and Grant, I. (1990). Reorganizing the "organic" disorders. Hospital and Community Psychiatry, 41, 722-724.

Wulff, H. R., Andur Pedersen, S. and Rosenberg, R. (1986). "Philosophy of Medicine: an Introduction". Blackwell Scientific, Oxford. 


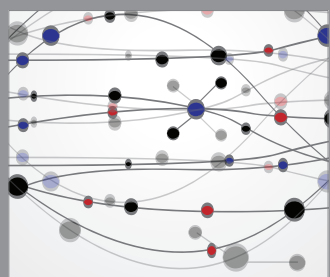

The Scientific World Journal
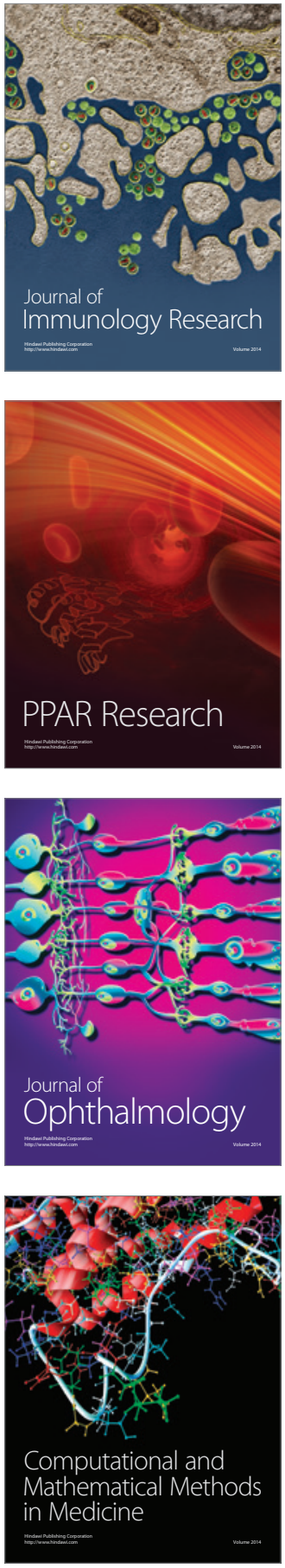

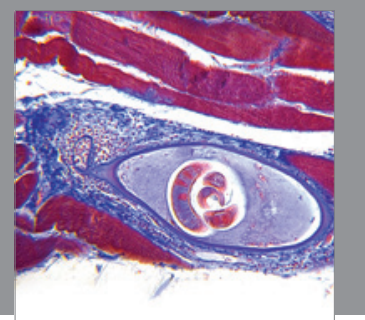

Gastroenterology

Research and Practice
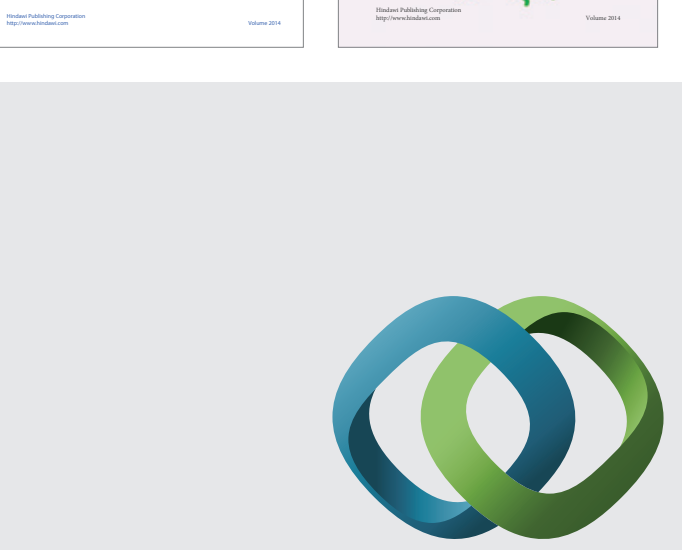

\section{Hindawi}

Submit your manuscripts at

http://www.hindawi.com
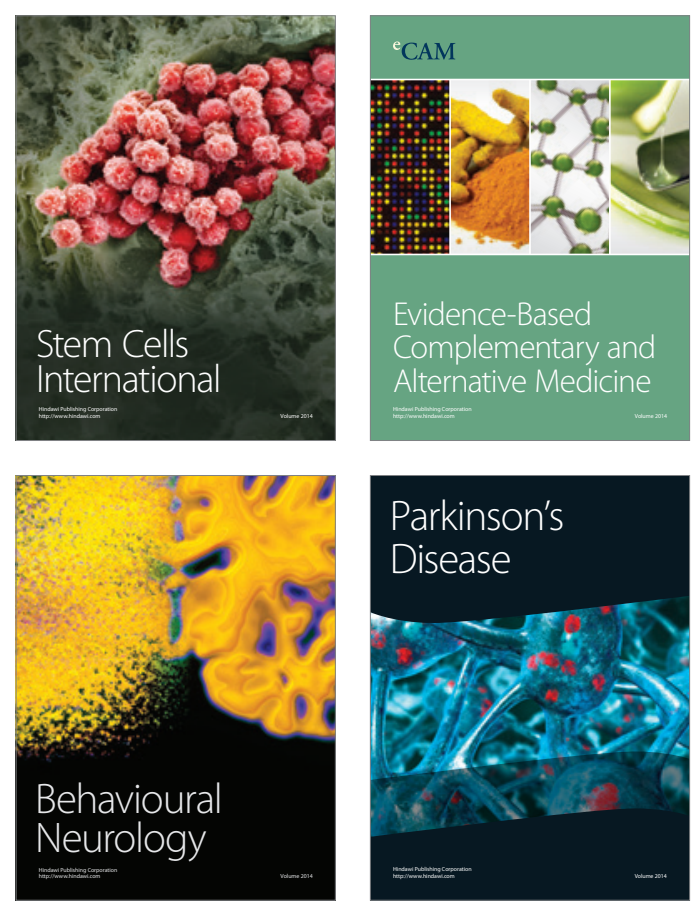

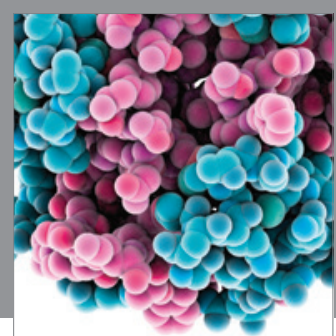

Journal of
Diabetes Research

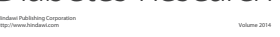

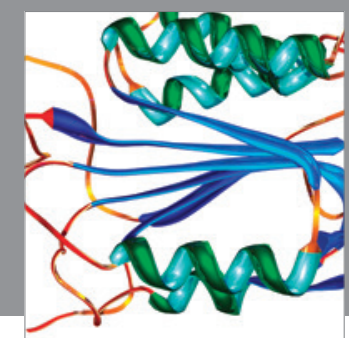

Disease Markers
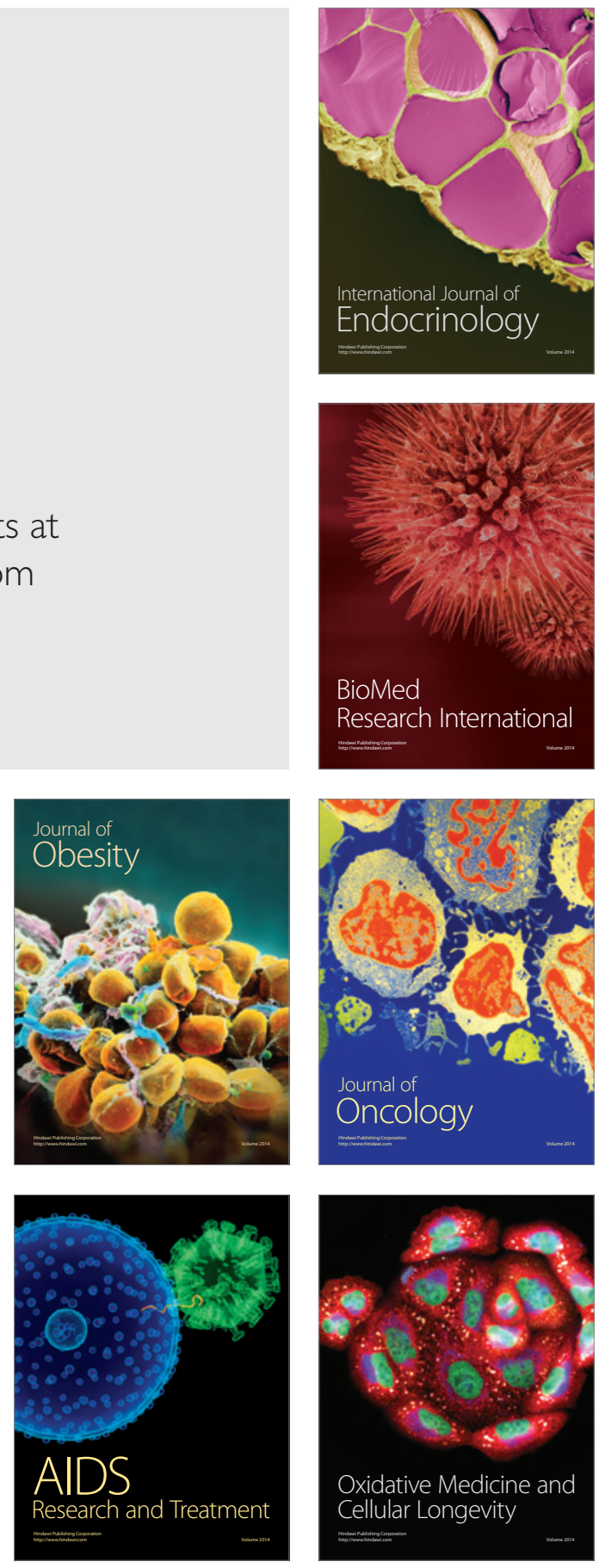